\title{
Correction to: A hybrid deep neural network approach to estimate reference evapotranspiration using limited climate data
}

\author{
Gitika Sharma $^{1}$ (D) $\cdot$ Ashima Singh $^{1} \cdot$ Sushma Jain ${ }^{1}$
}

Received: 9 December 2021 / Accepted: 9 December 2021 / Published online: 30 December 2021

(C) Springer-Verlag London Ltd., part of Springer Nature 2021

\section{Correction to: Neural Computing and Applications} https://doi.org/10.1007/s00521-021-06661-9

Unfortunately, the reference no. 52 contains a typo in the original publication of the article.

The corrected reference should read as below:

"52. Çiçek, E., Gören, S. Smartphone power management based on ConvLSTM model. Neural Comput \&
Applic 33, 8017-8029 (2021). https://doi.org/10.1007/ s00521-020-05544-9"

Publisher's Note Springer Nature remains neutral with regard to jurisdictional claims in published maps and institutional affiliations.

The original article can be found online at https:// doi.org/10.1007/s00521-021-06661-9.

Gitika Sharma

gsharma60_phd18@thapar.edu

1 Department of Computer Science, Thapar Institute of Engineering and Technology, Patiala, India 